\title{
ASK1 inhibition: a therapeutic strategy with multi-system benefits
}

\author{
Jacqueline M. Ogier ${ }^{1,2}$ (D) Bryony A. Nayagam ${ }^{3,4} \cdot$ Paul J. Lockhart ${ }^{1,2}$
}

Received: 20 August 2019 / Revised: 18 December 2019 / Accepted: 15 January 2020 / Published online: 14 February 2020

(C) The Author(s) 2020

\begin{abstract}
p38 mitogen-activated protein kinases (P38 $\alpha$ and $\beta$ ) and c-Jun N-terminal kinases (JNK1, 2, and 3) are key mediators of the cellular stress response. However, prolonged P38 and JNK signalling is associated with damaging inflammatory responses, reactive oxygen species-induced cell death, and fibrosis in multiple tissues, such as the kidney, liver, central nervous system, and cardiopulmonary systems. These responses are associated with many human diseases, including arthritis, dementia, and multiple organ dysfunctions. Attempts to prevent P38- and JNK-mediated disease using small molecule inhibitors of P38 or JNK have generally been unsuccessful. However, apoptosis signal-regulating kinase 1 (ASK1), an upstream regulator of P38 and JNK, has emerged as an alternative drug target for limiting P38- and JNK-mediated disease. Within this review, we compile the evidence that ASK1 mediates damaging cellular responses via prolonged P38 or JNK activation. We discuss the potential benefits of ASK1 inhibition as a therapeutic and summarise the studies that have tested the effects of ASK1 inhibition in cell and animal disease models, in addition to human clinical trials for a variety of disorders.
\end{abstract}

Keywords Apoptosis signal-regulating kinase $1 \cdot$ MAP3K5 $\cdot$ Clinical trial $\cdot$ ROS $\cdot$ MAPK $\cdot$ p38 $\cdot$ JNK

Mitogen-activated protein kinase kinase kinase 5 (MAP3K5), commonly known as apoptosis signal-regulating kinase 1 (ASK1), has emerged as a target for preventing p38 mitogen-activated protein kinase (MAPK14, 11, and 12/ P38 $\alpha, \beta$, and $\gamma$ ) and c-Jun N-terminal kinase (MAPK8, 9, and $10 / \mathrm{JNK} 1,2$, and 3 )-mediated cell death and disease. Both P38 and JNK are associated with reactive oxygen species (ROS)-induced disease ${ }^{1}$, and numerous studies have demonstrated that P38 and JNK inhibition ameliorates cell

\footnotetext{
${ }^{1}$ In mammals, four isoforms of P38 have been identified $(\alpha, \beta, \gamma$, and $\delta)$ and three isoforms of JNK (1,2, and 3) (reviewed in [1,2] respectively). However, the literature does not always specify which specific isoform(s) has been analysed. Throughout this review, specific isoforms are named if they are reported in the primary literature. If isoform-specific information is not available, we have used the general nomenclature P38 or JNK.
}

Jacqueline M. Ogier

Jackie.ogier@mcri.edu.au

1 The Bruce Lefroy Centre, The Murdoch Children's Research Institute, Parkville, Victoria, Australia

2 Department of Paediatrics, The University of Melbourne, Parkville, Victoria, Australia

3 Department of Audiology and Speech Pathology, The University of Melbourne, Parkville, Victoria, Australia

4 The Bionics Institute, East Melbourne, Victoria, Australia death [3-7]. However, complete inhibition of P38 or JNK in vivo is problematic, given that these ubiquitously expressed proteins are also critical for cell survival and homeostatic and/ or metabolic functions [8-11]. This is highlighted by the embryonic lethality of homozygous $P 38 \alpha$ and $J n k l / 2$ knockout mice $[12,13]$. In addition, homozygous $P 38 \beta$ knockout mice exhibit defective skeletal development [14] and homozygous Jnkl knockout mice spontaneously develop intestinal tumours [15]. Negative outcomes have also been reported due to partial $P 38$ or Jnk expression, with heterozygous $P 38 \alpha$ knockout mice developing progressive renal dysfunction [16] and heterozygous Jnkl knockout mice exhibiting altered weight gain, hyperinsulinaemia, insulin resistance, inflammatory cytokine disruption, and reduced viability [17]. Serious side effects have also been observed when pharmacological inhibition of P38 or JNK is pursued in vivo [14, 18, 19]. For example, pamapimod, a P38 ( $\alpha$ and $\beta$ ) inhibitor, did not significantly reduce joint swelling or improve mobility in individuals with rheumatoid arthritis in a phase II clinical trial. However, $35 \%$ of the participants receiving daily pamapimod $(300 \mathrm{mg})$ experienced infection, $20 \%$ developed a skin rash, $15 \%$ became dizzy, and $13 \%$ had elevated hepatic enzymes indicative of liver damage [20].

The pro-survival or pro-death outcomes of P38/JNK activity are largely dependent on the duration of activation. Shortterm activation is protective, inducing cellular repair 
mechanisms, whereas sustained P38/JNK phosphorylation initiates apoptotic and necrotic cell death cascades [21-26]. Therefore, an alternative therapeutic approach that targets a common, upstream molecule that is only activated by cell stress and capable of regulating both the P38 and JNK pathways is desirable. As an upstream converging point of cell stress signalling, ASK1 meets these criteria. Similar to P38 and JNK, ASK1 is ubiquitously expressed [27]. However, unlike P38 and JNK, ASK1 is primarily activated in response to cell stress (reviewed in Shiizaki et al. [28]). In particular, ASK1 activation is tightly controlled by redox signalling, due to the nature of its dithiol oxidoreductase binding partners, thioredoxin (TRX), glutaredoxin (GRX), and peroxiredoxin 1 (PRX1) [29-31] (Fig. 1). TRX, GRX, and PRX1 have redox active sites consisting of two cysteine residues that act as molecular switches [32]. When the cell is redox neutral, TRX, GRX, and PRX1 remain in a reduced state, bound to, and inactivating ASK1. TRX and PRX1 bind at the Nterminal domain of ASK1, and GRX at the C-terminus [30, 33-35]. Bound ASK1 is a substrate for ubiquitination and degradation [36]. Alternatively, cellular oxidative imbalance induces modifications of the cysteine sulphur atom of TRX, GRX, and PRX1. As a result, disulphide bonds form between the cysteine residues, inactivating TRX, PRX1, and GRX [37, 38]. Inactivated TRX, PRX1, and GRX dissociate from ASK1. Unbound ASK1 is then activated by autophosphorylation and a large multicomponent complex forms, referred to as the ASK1 signalosome [39]. This complex and associated ASK1 activity initiates the P38 and JNK signalling cascades [27, 40]. Importantly, ASK1 promotes the sustained and pro-apoptotic activation of $\mathrm{P} 38$ and JNK, without impacting short-term P38/JNK activity [41-43]. Therefore, ASK1 inhibition is unlikely to affect the pro-survival, homeostatic activities of P38 and JNK. This hypothesis is supported by the viability of Askl knockout mice, which are healthy and long-lived, and show no developmental abnormalities [42, 44-48].

The function of ASK1 as an upstream regulator of P38/JNKmediated disease has received considerable attention in recent literature. ASK1 is widely expressed in many tissues, including the kidney, liver, brain, heart, and lung [49]. Whilst ASK1 is
Fig. 1 In the redox neutral cell, dithiol oxidoreductases TRX, GRX, and PRX bind to and inactivate ASK1. However, cell stressors can induce cellular oxidative imbalance, which causes disulphide bonds to form between the cysteine residues of TRX, GRX, or PRX. As a result, TRX, PRX, and GRX dissociate from ASK1. Unbound ASK1 is then activated by autophosphorylation and a large multicomponent complex forms, referred to as the ASK1 signalosome. The ASK1 signalosome promotes the sustained activation of the P38 and JNK signalling cascades which have been associated with damaging inflammatory responses, cell death, and fibrosis in multiple tissues

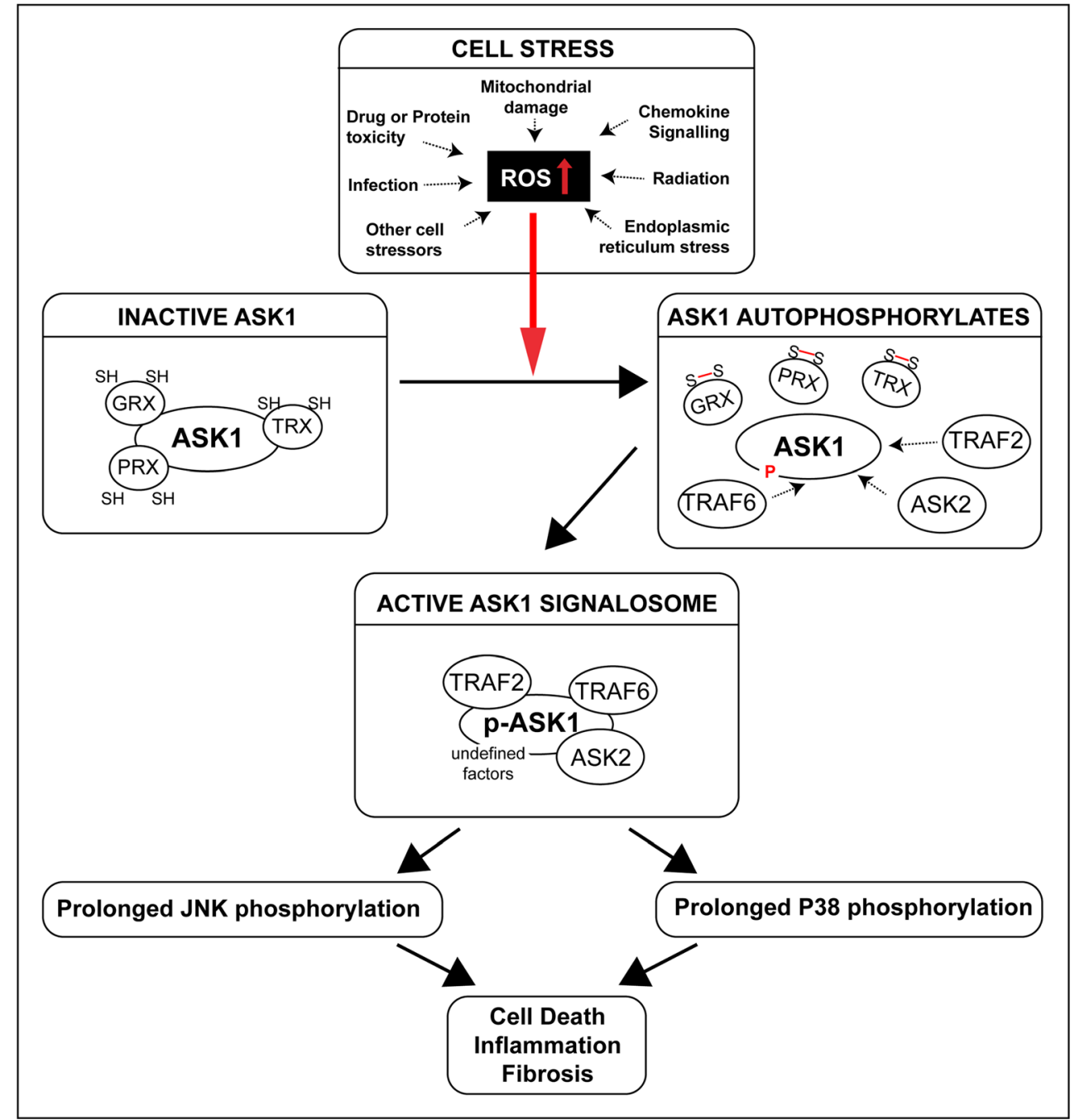


primarily activated in response to oxidative stress, other factors such as calcium overload, endoplasmic reticulum stress, infection, and receptor-mediated inflammatory signals, including lipopolysaccharide (LPS) and tumour necrosis factor (TNF) can also induce ASK1 signalling (reviewed in Shiizaki [28]). As a result, the role of ASK1 has been extensively investigated in disease models, with therapeutic potential observed in diseases of the kidney [50], liver [51], central nervous system [52, 53], joints [54], and cardiovasculature [47, 55, 56]. Subsequently, ASK1 inhibitors have been tested as a therapeutic in various disease settings, ranging from in vitro cellular studies to in vivo animal models and large clinical trials (Table 1). Herein, we discuss the potential of ASK1 inhibition for preventing disease, combining evidence from Askl knockout models, and research utilising ASK1 inhibitory compounds.

\section{Kidney disease: ASK1 modulation limits renal inflammation, apoptosis, and fibrosis}

Several models of kidney injury indicate that ASK1 activation drives renal damage via the ROS-P38 and JNK signalling

Table 1 A number of ASK1 inhibitors have been developed. The information regarding each is varied. Some have not been extensively studied, whilst others have been used to treat cell lines, small animals, and humans. $N A$ indicates information was not available

\begin{tabular}{|c|c|c|c|c|c|c|}
\hline Inhibitor & Supplier & Notable observations & IC50 & Formula & MW & Ref \\
\hline ВРyO-34 & Otava Chemicals & NA & $520 \mathrm{nM}$ & NA & NA & {$[57]$} \\
\hline GS-444217 & Gilead Sciences & $\begin{array}{l}\text { ATP competitive inhibitor. Reduced } \\
\text { pathological remodelling of the } \\
\text { pulmonary vasculature and the } \\
\text { right ventricle. Halts progression } \\
\text { of pulmonary hypertension in rats. } \\
\text { Reduces renal injury in multiple } \\
\text { rodent models }\end{array}$ & $2.9 \mathrm{nM}$ & NA & NA & {$[58-61]$} \\
\hline GS-459679 & Gilead Sciences & $\begin{array}{l}\text { ATP competitive inhibitor. Protects } \\
\text { against paracetamol-induced liver } \\
\text { injury in mice. Reduces myocardial } \\
\text { infarct size and cardiomyocyte } \\
\text { apoptosis after acute myocardial } \\
\text { ischemia/reperfusion in rats }\end{array}$ & $6.1 \mathrm{nM}$ & NA & NA & {$[43,62,63]$} \\
\hline $\begin{array}{l}\text { GS-4997 } \\
\quad \text { (selonsertib) }\end{array}$ & Gilead Sciences & $\begin{array}{l}\text { ATP competitive inhibitor. Antagonises } \\
\text { multidrug resistance in ABCB1- and } \\
\text { ABCG2-overexpressing cancer cells. } \\
\text { Reduces the progression of liver } \\
\text { damage in rodents } \\
\text { Phase II clinical trials against diabetes and } \\
\text { kidney disease } \\
\text { Phase III clinical trials for NASH }\end{array}$ & $3.2 \mathrm{nM}$ & $\mathrm{C}_{24} \mathrm{H}_{24} \mathrm{FN}_{7} \mathrm{O}$ & $445.502 \mathrm{~g} / \mathrm{mol}$ & [64-69] \\
\hline GS-627 & Gilead Sciences & $\begin{array}{l}\text { Decreased joint damage and inflammation in } \\
\text { a rat model of collagen-induced arthritis }\end{array}$ & $4.3 \mathrm{nM}$ & NA & NA & {$[70]$} \\
\hline K811 & $\begin{array}{l}\text { Kyowa Hakko Kirin } \\
\text { Co. Ltd }\end{array}$ & $\begin{array}{l}\text { Nitrogen-containing heterocyclic derivative } \\
\text { with high IC50 values for other kinases. } \\
\text { Slows disease progression and enhances } \\
\text { survival in a mouse model of amyotrophic } \\
\text { lateral sclerosis. Limits proliferation of } \\
\text { gastric cancer cells and reduces xenograft } \\
\text { tumour size in mice }\end{array}$ & $6 \mathrm{nM}$ & NA & NA & {$[71,72]$} \\
\hline K812 & $\begin{array}{l}\text { Kyowa Hakko Kirin } \\
\text { Co. Ltd }\end{array}$ & $\begin{array}{l}\text { Slows disease progression and enhances } \\
\text { survival in a mouse model of amyotrophic } \\
\text { lateral sclerosis. Note: lower specificity } \\
\text { than K811 }\end{array}$ & NA & NA & NA & {$[71,72]$} \\
\hline MSC2032964A & Tocris Biosciences & $\begin{array}{l}\text { Suppressed autoimmune inflammation in both } \\
\text { the spinal cord and optic nerves of a mouse } \\
\text { model of autoimmune encephalomyelitis }\end{array}$ & $93 \mathrm{nM}$ & $\mathrm{C}_{16} \mathrm{H}_{13} \mathrm{~F}_{3} \mathrm{~N}_{6} \mathrm{O}$ & $362.31 \mathrm{~g} / \mathrm{mol}$ & {$[52]$} \\
\hline SRT-015 & Seal Rock Therapeutics & $\begin{array}{l}\text { Targeted-liver specific ASK1 inhibitor } \\
\text { reduces hepatomegaly, fibrosis, and } \\
\text { steatosis of the liver }\end{array}$ & NA & NA & NA & $\begin{array}{l}\text { In } \\
\text { develop- } \\
\text { ment }\end{array}$ \\
\hline TC ASK 10 & Tocris Biosciences & $\begin{array}{l}\text { Prevents aberrant smooth muscle growth in } \\
\text { patients with chronic obstructive } \\
\text { pulmonary disease }\end{array}$ & $14 \mathrm{nM}$ & $\mathrm{C}_{21} \mathrm{H}_{21} \mathrm{~N}_{5} \mathrm{O} .2 \mathrm{HCl}$ & $432.35 \mathrm{~g} / \mathrm{mol}$ & {$[73,74]$} \\
\hline
\end{tabular}


cascades $[48,50,58]$. Moreover, studies in animal models of acute kidney injury have shown that Askl knockout or inhibition protects against tubular apoptosis, inflammation, and fibrosis $[48,50]$. For example, kidney function, as measured by blood urea nitrogen and serum creatinine levels, is superior in $A s k l^{-/-}$mice following renal ischaemia or unilateral ureteric obstruction when compared to wild-type mice [48, 50]. Lower leukocyte and macrophage infiltration rates also indicate that inflammation is reduced in the damaged kidneys of Ask1 knockout mice $[48,50]$. In rat models of kidney injury induced by auranofin, nephrotoxic serum injection, or unilateral ureteral obstruction, pre-treatment with the ASK1 inhibitor GS-444217 (30 mg/kg via oral gavage) suppresses the ROSASK1-P38/JNK response [59, 60]. As a result, kidney function is preserved, due to reduced tubular cell death, inflammation, and fibrosis. Similarly, GS-444217 slows the progression of renal disease in mice with streptozotocin-induced diabetic kidney disease [58]. Streptozotocin treatment damages pancreatic beta cells, causing insulin-dependent diabetes and development of diabetic kidney disease [75]. However, early intervention with GS-444217 reduces renal dysfunction and scarring. Late intervention (up to 15 weeks post diabetes onset) improves renal function and halts the progression of glomerular scarring, tubular injury, and renal inflammation [58]. These observations in the late intervention group suggest that a large treatment window exists for diabetic kidney disease [58]. This study also highlights the tolerability and bioavailability of GS-444217 when delivered in standard mouse chow $(0.1 \% \mathrm{w} / \mathrm{w})$, achieving plasma levels of approximately $20 \mu \mathrm{mol} / \mathrm{L}$.

The benefits of GS-444217 treatment are even more pronounced in the $\mathrm{db} / \mathrm{db} \mathrm{eNOS}^{-/-}$mouse model of progressive diabetic kidney disease. Endothelial nitric oxide synthase (eNOS) dysfunction is associated with diabetic nephropathy in humans and $\mathrm{eNOS}^{-/-}$mice have an enhanced susceptibility to kidney damage [76]. When crossed with genetically obese leptin receptor-deficient $(\mathrm{db} / \mathrm{db})$ mice, the resultant $\mathrm{db} / \mathrm{db}$ $\mathrm{eNOS}^{-/-}$progeny robustly model type II diabetic nephropathy. However, daily GS-444217 treatment reduces glomerular scarring, podocyte death, and renal fibrosis, preventing glomerular filtration changes and albuminuria in $\mathrm{db} / \mathrm{db} \mathrm{eNOS}^{-/-}$ mice [59].

Overall, multiple murine models with differing mechanisms of injury have provided evidence that pharmacological inhibition of ASK1 is able to preserve renal function via decreased cell death, inflammation, and fibrosis. These compelling results have subsequently led to a clinical trial testing ASK1 inhibition in humans with diabetic kidney disease (NCT02177786). In 2016, 333 participants took selonsertib (GS-4997) or a placebo, orally, once per day for 48 weeks as part of a phase II clinical trial [64]. The primary outcome measure was a change in glomerular filtration rate (eGFR) from baseline at week 48. This endpoint was not achieved, due to unexpected confounding factors, such as selonsertibmediated inhibition of creatinine secretion. However, post hoc analysis indicated that the $18 \mathrm{mg}$ selonsertib treatment group had a $71 \%$ eGFR reduction and a dose-dependent reduction of p-P38 was noted in all selonsertib treatment groups. This outcome highlights the difficult nature and apparent pitfalls of clinical trial design. However, the results do suggest that selonsertib has a protective effect that warrants further clinical investigation. Therefore, a phase III clinical trial is now underway, to evaluate whether selonsertib can slow the decline of kidney function, reduce the risk of kidney failure, or reduce the risk of death due to kidney disease in participants with diabetic kidney disease (NCT04026165). Notably, these outcome measures are broader than previous selonsertib trials, which will allow for the identification of improvements that may have otherwise been missed using narrower parameters (such as eGFR) to measure kidney function.

\section{Liver disease: ASK1 modulation prevents hepatocyte death, inflammation, and fibrosis in the liver}

Oxidative stress is a primary pathogenic cause of liver disease. For example, excessive ROS production has been associated with alcoholic liver disease, non-alcoholic fatty liver disease, hepatic fibrosis, hepatitis $\mathrm{C}$-induced damage, and poor surgical recovery (reviewed in Lach and Mikalak [77]). Recently, reports of paracetamol-induced, ROS-mediated liver injury have increased significantly, with drug toxicity now a leading cause of acute liver failure [78, 79]. At low doses, paracetamol metabolism generates the reactive metabolite $N$-acetyl- $p$-benzoquinone imine (NAPQI), which is detoxified via glutathione (GSH) conjugation. However, high paracetamol doses cause NAPQI production at a rate exceeding the liver's detoxification capabilities. NAPQI then forms mitochondrial DNA and protein adducts, inducing oxidative stress [80]. This redox signal causes ASK1-mediated, sustained JNK activation which leads to hepatocyte death [81, 82]. As such, ASK1 inhibition is proposed as a potential therapy for reducing paracetamol-induced liver injury [41].

In a proof of principle study, Nakagawa et al. [41] demonstrated that paracetamol-induced cellular damage in primary hepatocyte cultures was the result of ASK1-mediated JNK activation. Then, studies utilising Ask1 knockout mice demonstrated that ASK1 deficiency was protective against paracetamol-induced liver toxicity in vivo. Notably, the protection conferred in Askl knockout mice was greater than that observed in Jnk1 and Jnk2 knockout mice, suggesting that compensatory mechanisms may also be blocked by ASK1 inhibition [41]. Overall, three important observations were made regarding ASK1 activation in paracetamol-treated hepatocytes. First, transient P38 and JNK phosphorylation 
occurred in Askl knockout mice, yet prolonged phosphorylation (3-6 hours post treatment) was significantly reduced. This supports previous reports that ASK1 activation is required for the sustained, pro-apoptotic activation of JNK, whilst the pro-survival role of JNK is not impacted [41]. Secondly, long-term JNK activation was not completely inhibited in Ask1 knockout mice, illustrating that ASK1independent mechanisms of JNK activation exist [41]. However, the partial reduction of ASK1-mediated JNK1 or JNK2 activation achieved significant liver protection [41]. This suggests that incomplete ASK1 inhibition will be beneficial in vivo, even if functional limitations such as poor drug uptake in a target tissue prevent strong ASK1 inhibition.

The benefit of ASK1 inhibition was then demonstrated in wild-type C57BL/6 mice given hepatotoxic doses of paracetamol. ASK1 inhibition with GS-459679 reduced JNK phosphorylation and centrilobular necrosis [43]. As a result, mRNA levels of inflammatory factors (tumour necrosis factor (TNF-a), interleukin 6 (IL-6), and interleukin 61 beta (IL$1 \beta)$ ) remained low and paracetamol-treated mice maintained alanine aminotransferase (ALT) serum levels - which is a strong indicator of liver function [43, 62]. Importantly, GS459679 was protective when given 90 minutes after hepatotoxic paracetamol treatment [62]. This would suggest that a reasonable window of opportunity exists for liver protection in humans experiencing paracetamol overdose, particularly as paracetamol-induced liver damage occurs more slowly in humans than mice [62]. However, this hypothesis remains to be assessed clinically [62].

Beyond paracetamol-induced liver injury, ASK1 deficiency also reduces inflammation and hepatocyte death in a mouse model of obstructive cholestatic injury. In this model, surgical bile duct ligation causes inappropriate bile flow. The subsequent inflammatory response causes fibrosis and cirrhosis of the liver [83]. However, the inflammatory response and overall liver damage induced by bile duct ligation are much lower in Askl knockout mice when compared to controls. For example, infiltrating neutrophil and macrophage activity is reduced in the damaged livers of Ask1 knockout mice. Notably, Ask1 knockouts exhibit superior survival when compared to controls receiving the same surgery ( $78 \%$ vs. $51 \%$ surviving 21 days post surgery). Overall, serum levels of ALT, aspartate aminotransferase (AST), bilirubin, and bile acid are significantly lower in Askl knockout mice, which also suggests improved liver function when compared to controls [51]. These results indicate that ASK1 inhibition may prevent severe liver damage whilst diagnosis and treatment strategies are implemented in humans with cholestasis.

To date, ASK1 inhibition has predominantly been tested as a therapeutic strategy for limiting non-alcoholic steatohepatitis (NASH). NASH is the most severe form of non-alcoholic fatty liver disease (NAFLD) and the predominant cause of chronic liver failure. NAFLD affects over $25 \%$ of adults worldwide and $30 \%$ of people with NAFLD will develop NASH [84]. Hepatic oxidative stress, lipotoxicity, and inflammation drive the progression of NAFLD to NASH, causing cirrhosis, fibrosis, or hepatic carcinoma [84]. Currently, there is no approved pharmacological intervention for NASH. Instead, treatment is focused on reducing body weight and increasing physical activity. However, there is a growing need for alternate interventions as the prevalence of obesity and liver disease is increasing [84].

Similar to humans, mice consuming a high-fat diet develop heavy and fibrotic livers, laden with accumulating collagen and triglyceride [85]. However, homozygous Askl knockout mice fed a high-fat diet have healthy livers, comparable to wild-type normal-diet-fed mice [85]. In particular, liver weight and triglyceride content do not increase in Ask1 knockout mice fed a high-fat diet [85]. ASK1 inhibition also prevents $\mathrm{P} 38$ phosphorylation and caspase-3 cleavage in an alternate mouse model of NASH, the nodlike receptor family pyrin domain containing 3 (Nlrp3) knock-in transgenic mouse [65]. Nlrp3 KI mice develop hepatic inflammation and fibrosis due to aberrant NLRP3mediated inflammation. However, ASK1 inhibition with selonsertib significantly reduces liver fibrosis in Nlrp3 KI mice (as demonstrated by a $33.5 \%$ reduction in hydroxyproline levels when compared to untreated Nlrp3 KI controls). Moreover, serum ALT levels of untreated Nlrp3 KI mice are twice as high as the selonsertib-treated Nlrp3 KI mice, indicating that liver function is retained when selonsertib is used [65]. Selonsertib has now been tested as a treatment for NASH and liver fibrosis in humans.

In 2016, a phase II clinical trial determined that selonsertib was safe and effective in NASH patients with stage 2 or 3 liver fibrosis. In this trial, participants received 24 weeks of openlabel, oral selonsertib treatment (6 or $18 \mathrm{mg}$, daily). Outcomes were assessed by comparing pre- and post-treatment liver biopsies, collagen content, fat content, magnetic resonance elastography, and serum markers of liver injury. Most study participants had stage 3 fibrosis, hepatocellular ballooning, and diabetes mellitus at the beginning of the trial. However, at the trial's conclusion, the progression of liver disease was notably reduced in selonsertib-treated participants. After 24 weeks of treatment, 13 of 30 individuals in the $18 \mathrm{mg}$ selonsertib group and 8 of 27 in the $6 \mathrm{mg}$ selonsertib group had a one or more stage reduction in fibrosis. Reduced fibrosis was also associated with decreased liver stiffness, collagen content, and lobular inflammation [66, 67]. The observed reduction of fibrosis was particularly exciting, as fibrosis is a strong predictor of liver failure in NASH [67]. Overall, the trial provided evidence that selonsertib treatment is safe and efficacious for individuals with NASH [67]. Selonsertib subsequently progressed to a larger phase 
III clinical trial for NASH-induced compensated cirrhosis (NCT03053063). This trial was designed to last 240 weeks. However, the trial was discontinued after 48 weeks. The reasoning for this discontinuation is unknown, as the trial results are not yet available. Two other clinical trials utilising selonsertib for NASH treatment are still in progress; a phase II trial for NASH-induced bridging fibrosis (NCT03053050), and a phase II trial combining selonsertib, cilofexor (GS-9674, a non-steroidal FXR agonist), and firsocostat (GS-0976, an ACC inhibitor) for NASH-induced fibrosis (NCT03449446).

\section{Brain disorders: ASK1 deficiency limits neurodegeneration}

Neurodegenerative disorders are a significant and growing health and economic burden. For example, 50 million people globally are living with dementia and this number is expected to increase to 131 million by 2050 , due to the ageing population $[86,87]$. Of all the neurodegenerative disorders, Alzheimer's disease is the most prevalent, accounting for approximately $70 \%$ of dementia cases. The primary pathological features of Alzheimer's are the presence of plaques and neurofibrillary tangles in the brain, composed predominantly of beta-amyloid and phosphorylated Tau, respectively. Betaamyloid impairs mitochondrial function, resulting in excessive ROS production (reviewed in Reddy and Beal [88] and Spuch et al. [89]). An in vitro study of primary neuronal cells derived from embryonic mice suggested that this altered redox state mediates cell death via ASK1-JNK activation [53]. Furthermore, a comparison of neuronal cultures derived from wild-type and homozygote Askl knockout mice indicated that ASK1 deficiency affords remarkable protection against betaamyloid-induced cell death. After three days of exogenous beta-amyloid treatment, only $20 \%$ of the wild-type neurons remained viable compared with $70 \%$ of the $A s k I^{-/-}$neurons [53]. In this model, ASK1-JNK activation is the primary effector of neuronal cell death. However, $30 \%$ of $A s k I^{-/-}$cells still died, showing that there are ASK1-independent pathways for neuronal cell death [53]. In vivo studies utilising the 5XFAD mouse model of Alzheimer's disease suggest that P38 activation also mediates beta-amyloid-induced neurodegeneration. 5XFAD transgenic mice express a mutant form of the amyloid precursor protein (APP) containing five familial Alzheimer's mutations. These mutations have an additive effect, driving beta-amyloid overproduction, and the transgene's Thyl promoter ensures brain-specific expression [90]. As a result, 5XFAD mice develop beta-amyloid plaques, which cause progressive neuronal cell death. By four months of age, 5XFAD mice have significant memory deficits $[90,91]$. However, this deficit is reduced in homozygous Ask1 knockout 5XFAD mice, as measured by the passive avoidance test. P38 phosphorylation is strikingly lower in the $5 \mathrm{XFAD} / \mathrm{Ask} \mathrm{I}^{-/-}$mouse cerebrum, when compared to $5 \mathrm{XFAD} / \mathrm{Ask}^{+/+}$controls. Interestingly, JNK phosphorylation did not change, which contrasts with the JNK activation observed in cultured, beta-amyloid-treated neurons. However, it is likely that the alternate activation of P38 and JNK is due to different in vitro/in vivo cell culture conditions. Alternatively, it may indicate that neurodegeneration is driven by more than one apoptotic pathway. Nevertheless, ASK1 deficiency reduced both P38and JNK-mediated forms of neurodegeneration, which highlights the strength of ASK1 as a common upstream target.

Parkinson's disease is another common neurodegenerative disease characterised by oxidative stress and activation of the ASK1-P38 and JNK pathways. In vitro, Hu et al. [92] observed significant and persistent ASK1 phosphorylation in dopaminergic neurons (MN9D cell line) treated with the neurotoxic compound oxidopamine. However, targeted ASK1 knockdown, using lentiviral-delivered short hairpin RNA, significantly enhances oxidopamine-treated MN9D survival. In vivo, the same lentiviral shRNA against Askl is protective against oxidopamine toxicity. ShRNA was injected into the mouse substantia nigra pars compacta, reducing ASK1 levels by $\sim 80 \%$ in tyrosine hydroxylase-positive dopaminergic neurons (as measured by western blot analysis). Three weeks after Askl knockdown, $3 \mu \mathrm{g}$ of oxidopamine was injected into the left striatum. Seven days after oxidopamine treatment, immunoblotting showed that phosphorylation of both P38 and JNK was significantly reduced in the ASK1-deficient pars compacta. Moreover, histology indicated that twice as many dopaminergic neurons survived in the knockdown group. Behavioural testing, including the corner test and apomorphine-induced rotation test, showed that motor function in the oxidopamine-treated Ask1 knockdown mice was significantly better when compared to oxidopamine-treated wild-type mice [92]. The benefits afforded by incomplete Askl knockdown (80\%) in oxidopamine-treated mice indicate that partial ASK1 inhibition may represent a powerful therapeutic tool, even if complete inhibition is difficult to achieve in a target tissue.

As ASK1-mediated activation of P38 and JNK had been consistently observed in neurons after oxidopamine treatment, in both the MN9D cell line and mice, Hu et al. then examined whether this pathway was active in post-mortem tissue derived from individuals with Parkinson's disease. Immunofluorescence analysis demonstrated significantly more p-ASK, p-JNK, and p-P38 staining in the Parkinson's affected tissue compared to matched control samples [92]. Collectively, the observations of $\mathrm{p}-\mathrm{ASK} 1, \mathrm{p}-\mathrm{P} 38$, and $\mathrm{p}-\mathrm{JNK}$ in Parkinson's model systems and human tissue provide strong evidence that ASK1 is a relevant therapeutic target for Parkinsonian disorders. 


\section{Inflammatory disease: ASK1 modulation limits damaging immune responses}

Recent studies have associated ASK1-P38 and JNK with the damaging inflammatory responses underlying immunemediated disease, such as multiple sclerosis, amyotrophic lateral sclerosis, and arthritis [52, 54, 70, 71, 93].

\section{Neuroinflammation}

Multiple sclerosis (MS) is a disease characterised by immunemediated destruction of the myelin sheath within the central nervous system. In contrast, amyotrophic lateral sclerosis (ALS) is caused by degeneration of the motor neurons within the brain and spinal cord. The aetiopathogeneses of ALS and MS are thought to be quite different; however, the progression of both diseases is characterised by a strong immune response, which may include microglia and astrocyte activation and monocyte or $\mathrm{T}$ cell immune responses (reviewed in Zhao et al. [94]).

In a mouse model of MS, where myelin oligodendrocyte glycoprotein (MOG) injections are used to induce T cellmediated autoimmune encephalomyelitis, ASK1 deficiency affords significant protection against several diseaseassociated phenotypes. For example, MOG-treated wild-type mice develop significant visual impairment, whereas similarly treated Askl knockout mice do not [52]. Optic nerve histology shows significantly reduced infiltrating inflammatory cells and axonal degeneration in $A s k I^{-/-}$samples [52]. Spinal cord histopathology also indicates that CNS inflammation and glial activation is drastically reduced in MOG-treated $A s k 1^{-/-}$mice. In vitro experiments using LPS-treated astrocytes and microglia suggest that the underlying mechanism of MOG treatment is toll-like receptor 4 and 9 (TLR4 and TLR9)-induced P38 signalling. The TLR-P38 pathway also enhanced proinflammatory TNF $\alpha$ and nitric oxide synthase activity, which drives demyelination. Both TLR4 and TLR9 are associated with ROS production, providing a logical mechanism for ASK1-mediated P38 activation. The proposed TLR-ROSASK1-P38-chemokine pathway to demyelination requires further investigation in vivo. However, chemokine production, inflammation, and demyelination are reduced in MOGtreated $A s k I^{-1-}$ mice, supporting the mechanism proposed. Overall, it seems likely that the reduced axonal degeneration and demyelination observed in $A s k 1^{-1-}$ mice with MOGmediated autoimmune encephalomyelitis is the result of reduced P38-mediated inflammation [52]. Importantly, ASK1 inhibition (MSC2032964A) achieves similar attenuation of demyelination within the same mouse model and also blocks lipopolysaccharide-binding protein-induced ASK1-P38 activation in cultured mouse astrocytes, providing evidence that ASK1 inhibition may be able to slow the progression of MS [52].
ASK1 deficiency also modulates disease progression in the SOD1 transgenic mouse model of ALS. SOD1 mice carry the familial $\mathrm{Cu} / \mathrm{Zn}$-superoxide dismutase (SOD1) mutation, associated with ALS. In this model, aggregates of mutant SOD1 accumulate in the mitochondria causing ROS production, ASK1 phosphorylation, and neuronal cell death mediated by P38 but not JNK [95-97]. Ask1 knockout does not alter the age of disease onset or prevent ALS lethality in the SOD1 mouse model. However, ASK1 deficiency does mitigate motor neuron death as the disease progresses. As a result, $A s k 1^{--}$ SOD1 mice survive, on average, one month longer than Ask $1^{+/+}$SOD1 mice [98]. ASK1 inhibitors K811 and K812 also reduce ALS pathology in vitro and in vivo. For example, primary spinal cord cultures derived from wild-type mice were infected with lentivirus expressing either a wild-type or mutant form of SOD1. The number of surviving motor neurons in the spinal cord cultures expressing mutant SOD1 was significantly lower than those expressing wild-type SOD1. However, treatment with K811 or K812 completely inhibited mutant SOD1-induced motor neuron death. Similarly, K811 or K812 treatment reduced glial activation and prevented motor neuron death in the SOD1 mouse model. This improved the life expectancy of SOD1 mice by three weeks [71]. The extended lifespan of SOD1 mice treated with ASK1 inhibitors is of particular significance, as riluzole and edaravone, the FDA-approved ALS treatments, do not alter the lifespan of SOD1 transgenic mice $[99,100]$. If ASK1 inhibition is able to achieve a similar reduction of motor neuron death in ALSaffected individuals as observed in the ALS mouse model, then the therapeutic effect of ASK1 inhibition would be significantly greater than that of either riluzole or edaravone. However, ASK1 inhibition has not yet been investigated in human tissues derived from individuals with ALS.

\section{Joint inflammation, arthritis, and bone repair}

Rheumatoid arthritis is an autoimmune disease characterised by chronic inflammation, leading to bone and cartilage destruction within the joints. Upregulated P38 activity is a key contributor to this inflammatory response and a number of P38 inhibitors have been tested as potential treatments [6, 54, 101]. However, P38 inhibitors have failed to achieve significant disease attenuation in vivo, possibly because P38 has both pro-and anti-inflammatory effects [11, 24]. Alternatively, low doses may have been used to avoid the liver toxicity frequently described when P38 inhibitors are used in vivo, and such doses may be insufficient to achieve meaningful disease attenuation.

Interestingly, experiments utilising synoviocytes derived from individuals with rheumatoid arthritis indicate that JNK activation occurs concurrently with P38 activation and that both must be inhibited to effectively limit inflammatory responses [70]. Therefore, Mninch et al. [54] characterised a 
mouse model of rheumatoid arthritis to assess the role of ASK1 as an upstream regulator of P38/JNK-mediated inflammation. In this model, serum from arthritic transgenic $\mathrm{K} / \mathrm{BxN}$ mice is transferred to naive mice. The host's inflammatory cells, including neutrophils and mast cells, activate in response to the transferred antibodies. This results in elevated levels of inflammatory cytokines, causing significant injury and arthritis within days [102, 103]. However, serum levels of inflammatory cytokines are reduced in treated Ask1 knockout mice compared to C57BL/6 controls. As a result, Ask1 knockouts experience significantly less swelling of the joint and reduced cartilage destruction and bone damage when compared to $\mathrm{K} / \mathrm{BxN}$-injected wild-type mice [54]. ASK1 inhibition has also been tested in the collagen-induced arthritis rat model [70]. Like the $\mathrm{K} / \mathrm{BxN}$ serum transfer model, immunisation with type II collagen induces a significant inflammatory response in the host animal, causing arthritis symptoms to manifest within three weeks [104]. However, treatment with the ASK1 inhibitor GS-627 significantly reduces joint damage and swelling in collagen-treated rats [70]. Combined, these two murine models of arthritis suggest that ASK1 inhibition can mitigate the damaging inflammatory response underpinning rheumatoid arthritis.

Whilst rheumatoid arthritis is a systemic inflammatory disease, osteoarthritis tends to manifest as age- or injury-related cartilage destruction. When the joint is initially injured, ROS, cytokines, and growth factors are released into the joint space. As a result, chondrocytes become hypertrophic and proliferative, and the extracellular matrix is degraded. The slow degradation of cartilage increases mechanical stress within the joint, eventually leading to bone remodelling and complete cartilage destruction. Oxidative stress is strongly associated with chondrocyte hypertrophy, mediated by ASK1-P38 and JNK $[105,106]$. However, ASK1 inhibition using exogenous thioredoxin blocks the TNFR1-ASK1-P38/JNK signalling pathway in cultured synovial fibroblasts derived from human osteoarthritis knee tissue $[93,106,107]$. In vivo, chondrocyte hypertrophy is significantly reduced in untreated two-year-old $A s k 1^{-1-}$ mice, when compared to age-matched $A s k 1^{+/+}$mice [93]. As a result, $A s k 1^{-/-}$mice experience significantly less age-related cartilage degeneration, proteoglycan loss, and calcification of the joints, compared to wild-type controls [93]. Similarly, two surgically induced mouse models of osteoarthritis - one severe (partial meniscectomy) and one mild (joint destabilisation/injury) — suggest that ASK1 deficiency prevents cartilage damage and enhances bone repair [93]. In the severe osteoarthritis model, wild-type mouse joints exhibit extensive cartilage degradation, proteoglycan loss, fibrosis, and inflammatory infiltrates at four weeks post surgery. However, both heterozygous and homozygous Ask1 knockout mice have significantly reduced bone thinning, cartilage degradation, and fibrosis [93]. Similar results were achieved in the milder joint destabilisation model, with
$A s k 1^{-/-}$mice showing reduced cartilage hypertrophy and proteoglycan loss eight weeks after surgery, when compared to controls.

Human cartilage collected from individuals with both osteoarthritis and rheumatoid arthritis demonstrate significant ASK1 phosphorylation [70, 93]. This suggests that the benefits of ASK1 deficiency in murine models of arthritis may also be relevant to human disease. Collectively, the research performed to date suggests that ASK1 inhibition is a potential therapeutic strategy to reduce joint degradation in rheumatoid and osteoarthritis. Inflammation and chondrocyte activity are also important for bone formation and repair. Therefore, the observation that ASK1 induces P38/JNK-mediated chondrocyte hypertrophy and death also suggests that ASK1 inhibition may be useful for enhancing fracture repair [93, 107]. Indeed, bone mineralisation and formation is accelerated in Ask1 mice [107]. However, further studies are required to ascertain the viability of ASK1 inhibition for enhancing human bone repair.

\section{Cardiopulmonary disease: ASK1 mediates heart and lung phenotypes associated with invasive smooth muscle cells}

Smooth muscle cells have an important role for maintaining airway structure and function. However, aberrant smooth muscle activity can cause chronic obstructive pulmonary disease (COPD). In particular, smooth muscle remodelling can impede airway contractility and relaxation, causing thick masses that obstruct airflow (reviewed in Yan et al. [108]). Smooth muscle cells in individuals with COPD show remarkably high p-ASK1 protein levels [73]. Therefore, ASK1 inhibition may represent a therapeutic intervention to limit COPD airway remodelling. In vitro studies have shown that ASK1 inhibition, using the compound TC ASK 10 or siRNA Ask1 knockdown, is able to prevent smooth muscle growth and migration by inhibiting P38 and JNK1 and 2 signalling [73, 74]. The benefits of ASK1 inhibition have not yet been investigated in COPD animal models. Instead, animal studies have focused on the pathological role of ASK1-mediated smooth muscle cell activity during cardiovascular remodelling.

Smooth muscle cells maintain the structural integrity and dynamic properties of blood vessels [109]. However, smooth muscle cells can also cause vascular thickening, known as neointimal hyperplasia after a surgical vascular injury [55]. Similarly, smooth muscle remodelling after myocardial injury can damage the ventricle, causing catastrophic cardiac dysfunction [47]. In both cases, p-ASK1JNK-mediated apoptosis plays an essential role in the remodelling process and subsequent dysfunction. However, ASK1 inhibition limits pathological vascular remodelling 
in animal models. For example, when a balloon catheter is inserted into an artery in rats, the intimal endothelial lining is mechanically removed, causing a distending mural injury [110]. Within two minutes of injury, ASK1 phosphorylation occurs, with maximal levels observed five minutes after injury. Notably, ASK1 phosphorylation is elevated sevenfold compared to uninjured controls [55]. ASK1-mediated P38 and JNK activation subsequently promotes vascular smooth muscle cell migration and proliferation. As a result, rats with vascular injury develop neointimal hyperplasia within two weeks [55]. However, pre-treatment infusion of adenovirus vectors expressing a dominant-negative ASK1 mutant (DN-ASK1) in the target artery reduces smooth muscle infiltration and prevents vascular thickening after injury [55]. This outcome has been replicated in mice, with neointimal formation significantly reduced in $A s k 1^{-/-}$mice subsequent to an experimental vascular injury induced by cuff placement around the femoral artery [55]. In other mouse models of myocardial infarction or pressure overload-induced cardiac injury, post-injury remodelling impairs cardiac contractility, and changes the ventricular dimensions of wild-type mice [47]. However, $A s k l^{-/-}$mice retain cardiac contractility and exhibit reduced fibrosis compared to wild-type controls [47]. ASK1 inhibition (GS-444217) also prevents pathological vasculature remodelling in two independent rodent models of pulmonary arterial hypertension. In the first model, a single injection of the plant toxin monocrotaline is used to induce pulmonary vascular remodelling. Four weeks after the injection, a peak increase in pulmonary pressure and right ventricle hypertrophy are observed in wild-type rats. However, pulmonary pressure and right ventricle hypertrophy are significantly reduced in mice treated with GS-444217 (0.2\% in chow). Importantly, both early (day 7) or late (day 14) interventions are able to significantly improve heart function. Likewise, GS-444217 prevents right ventricle remodelling and pulmonary hypertension in rats injected with the cardiotoxic tyrosine-kinase inhibitor semaxanib and subjected to four weeks of hypoxia [61].

In humans, ASK1 and P38 $\alpha$ have also been associated with the pathophysiology of pulmonary arterial hypertension by enhancing the proliferation of fibroblasts and smooth muscle cells [7, 61]. Combined, these findings indicate that ASK1 inhibition may be able to limit pathogenic cardiac or vascular smooth muscle cell remodelling and slow the onset of heart failure. However, a phase II clinical trial, testing selonsertib as a therapeutic for pulmonary arterial hypertension did not achieve its primary endpoint, which was a reduction in baseline pulmonary vascular resistance, as measured by right heart catheterisation [68]. The 24-week randomised trial (NCT02234141) compared three daily doses $(2 \mathrm{mg}, 6 \mathrm{mg}$, or $18 \mathrm{mg}$ ) of selonsertib to placebo in 150 individuals with pulmonary arterial hypertension. There was a correlation of reduced pulmonary vascular resistance in the higher dose groups ( $6 \mathrm{mg}$ and $18 \mathrm{mg}$ ); however, this was confounded by an increase from baseline vascular resistance in the low-dose group. No treatment groups showed a statistically significant change; however, this may have been due to the large standard deviation observed within each group. For most secondary measures, there was no change from baseline in people who received selonsertib. However, the number of participants that had an improved WHO functional class (a system for defining the severity of an individual's symptoms and how they impact on day-to-day activities) was notably higher in all selonsertib groups (14-19\%) when compared to the placebo group (3\%).

\section{Discussion}

The stress-activated MAP kinases P38 and JNK have been associated with apoptosis, inflammation, and fibrosis in multiple disease states affecting the kidney, liver, brain cardiopulmonary systems, and joints. In particular, ROS-mediated, prolonged activation of $\mathrm{P} 38$ or JNK is thought to induce damaging cellular responses. In the past, numerous attempts have been made to prevent ROS-mediated disease through the use of antioxidants, small molecule inhibitors, or RNA interference. However, the therapies directed at ROS, P38, or JNK have been disappointing, with a number of limitations being observed. For example, dysregulated ROS production is cytotoxic. However, ROS signalling remains an integral part of normal cellular and physiological function. It is therefore important to target redox stress, without affecting off-target ROS activity. Likewise, P38 and JNK phosphorylation is important for both pro-survival and pro-death signalling, largely dependent on the duration of activity. Therefore, inappropriate inhibition of transient $\mathrm{P} 38 / \mathrm{JNK}$ can have critical implications for cellular homeostasis in otherwise normal functioning cells.

In some disease states, P38 and JNK appear to be interchangeably activated, emphasising the potential limitations associated with direct inhibition of either molecule in isolation, whereas ASK1 inhibition has repeatedly been shown to selectively regulate prolonged, apoptotic P38 and JNK activation, but not pro-survival mechanisms $[47,48,50]$. Similarly, ASK1 inhibition is a promising alternative to antioxidant supplementation, as it can reduce the pathological consequences of oxidative stress, without impacting physiological ROS activity.

Many ASK1 inhibitors possessing good potency and selectivity profiles have now been developed (Table 1). These inhibitors are primarily available as small molecules with excellent oral bioavailability and are capable of achieving stable plasma concentrations, with a long half-life and widespread distribution across tissues, including the brain $[52,59,62,73]$. A number of clinical trials have shown that ASK1 inhibition is 
well tolerated in humans $[64,66,68]$. There is, however, one major point of concern that is relevant to any therapeutic target within an apoptotic pathway - the potential for aberrant cell survival. For example, reduced ASK1 expression has been associated with aggressive hepatic tumours [111, 112]. Alternatively, enhanced ASK1 expression has a role in the carcinogenesis of human gastric cancer [113]. ASK1 inhibition slows the growth of gastric cancer xenografts in mice and $A s k 1^{-/-}$mice have fewer and smaller tumours than wild-type controls in the $N$-methyl- $N$-nitrosourea chemically induced gastric tumourigenesis model $[72,113]$. Moreover, plateletspecific deletion of ASK1 prevents tumour metastasis in mice that have established lung cancer, induced by the injection of either melanoma or Lewis lung carcinoma cells $[69,114]$. Thus, it is apparent that ASK1 can function as both a tumour suppressor or tumour promoter, depending on the cellular responses induced by ASK1 modulation. It is also worth noting that $A s k l^{-1}$ mice are healthy and long-lived, suggesting that pharmacologically mediated ASK1 inhibition is unlikely to have serious side effects [42, 44-48]. In humans, the ASK1 inhibitor selonsertib has been administered for 12 months in clinical trials, with no increase in malignancies or other significant detrimental effects reported [64]. It seems likely that compensatory cell death mechanisms can prevent neoplastic growth during ASK1 inhibition; however, the potential of carcinogenesis must be considered. It is conceivable however, that individuals with tumours susceptible to ASK1 inhibition could benefit from an adjuvant ASK1 inhibitory therapy that not only enhances the anti-neoplastic effects of chemotherapy, but also affords protection against the frequently observed toxic effects that platinum-based compounds have in the brain, kidney, and ear.

Overall, the evidence available suggests that procarcinogenic outcomes resulting from reduced ASK1 activation are unlikely to represent an immediate concern. However, some potential for enhanced bleeding, altered heat production, and oxygen consumption has been observed in $A s k l^{-/}$mice $[115,116]$. These observations suggest that ASK1 inhibition may impact post-operative care and may not be appropriate for individuals with metabolic disease. However, another noteworthy observation is that ASK1 deficiency attenuates lung injury in ventilated mice [117]. Ventilated $\mathrm{Askl}^{-/-}$mice also maintain a more stable heart rate and better oxygen saturation than wild-type controls [117]. Therefore, ASK1 inhibition may provide benefits at the acute and post-ventilation stages of treatment, preventing acute respiratory distress syndrome [117]. Further investigation should determine if similar outcomes are observed in humans. However, it is clear that the potential benefits of ASK1 inhibition will be achieved in a tightly controlled, disease-specific context.

As discussed in this review, ASK1 inhibition has not met defined endpoints in some clinical trials. It is not yet clear what caused these outcomes; however, it may be that ASK1 inhibition had a positive effect that was not captured due to trial methodology. The species effect is another factor, and it is possible that a Homo sapiens-tailored approach is required to reap the full benefits of ASK1 inhibition. For this to occur, the publication of full clinical trial results is required. Alternatively, compensatory mechanisms may be at play. For example, numerous studies have shown that ASK1 inhibition significantly reduces unwanted cell death, but in most cases P38 or JNK activity was not completely blocked [50, 53]. At least 14 MKKKs exist that activate the JNK pathway [118], so it is unlikely that ASK1 inhibition is able to completely prevent cell death. Additional MAPKKindependent cell death signals may also be driving apoptosis. Notably, the fundamental interaction of p-ASK1 with specific P38 and JNK isoforms has been limited by a lack of tools for discerning between highly similar proteins. Further investigation will be required to address this issue. Nevertheless, the benefits of ASK1 inhibition or deficiency in pre-clinical disease models are clear. ASK1 does not have to be completely inhibited to have a strong effect and ASK1 inhibition has successfully attenuated disease in models with established tissue damage [58, 62, 92]. Such favourable outcomes suggest that an achievable 'treatment window' exists and that ASK1 modulation may benefit human health.

\section{Summary}

ASK1 is a widely expressed and evolutionarily conserved mediator of cell death, fibrosis, and inflammation [49]. The reported beneficial effects of ASK1 deficiency are widespread, indicating that ASK1 inhibition may be a particularly useful therapy in multi-system disorders, such as diabetesinduced tissue damage. Indeed, ASK1 inhibition is beneficial in models of diabetes or high-fat diet-related damage of the cardiovasculature [85, 119], liver [85], kidney [58], and brain [45]. Furthermore, ASK1 inhibition or deficiency has repeatedly limited pathologic activation of $\mathrm{P} 38$ or JNK in a diseasespecific manner [46-48, 50, 55, 59].

Thus far, the argument for ASK1 inhibition against ROSP38/JNK-mediated disease is convincing. However, additional disease-specific research is required to fully elucidate the potential benefits of ASK1 inhibition. Within this review, we have illustrated the benefits afforded by ASK1 deficiency in numerous and varied disease models. Many examples now suggest that ASK1 inhibition can limit damaging cell death, inflammation, and fibrosis of the kidney, liver, central nervous system, heart, and lungs. Furthermore, ASK1 inhibition may slow the progression of inflammatory diseases such as multiple sclerosis, arthritis, and amyotrophic lateral sclerosis. Overall, significant protective effects have been observed in numerous tissue types. ASK1 inhibition has great potential 
and may ultimately be used to achieve lasting, improved human health.

Acknowledgements The authors are supported by the Garnet Passe and Rodney Williams Memorial Foundation (PhD Research scholarship to JMO; Research Fellowship to BAN) and the Vincent Chiodo Foundation (PJL). Additional infrastructure funding to the Murdoch Children's Research Institute was provided by the Australian Government National Health and Medical Research Council Independent Research Institute Infrastructure Support Scheme and the Victorian Government's Operational Infrastructure Support Program.

Author contributions For this review, JMO performed the literature search and wrote the first draft. All authors contributed to manuscript conceptualisation and editing.

\section{Compliance with ethical standards}

Conflict of interest The authors declare that they have no conflict of interest.

Open Access This article is licensed under a Creative Commons Attribution 4.0 International License, which permits use, sharing, adaptation, distribution and reproduction in any medium or format, as long as you give appropriate credit to the original author(s) and the source, provide a link to the Creative Commons licence, and indicate if changes were made. The images or other third party material in this article are included in the article's Creative Commons licence, unless indicated otherwise in a credit line to the material. If material is not included in the article's Creative Commons licence and your intended use is not permitted by statutory regulation or exceeds the permitted use, you will need to obtain permission directly from the copyright holder. To view a copy of this licence, visit http://creativecommons.org/licenses/by/4.0/.

\section{References}

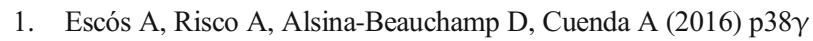
and p38 mitogen activated protein kinases (MAPKs), new stars in the MAPK galaxy. Front Cell Dev Biol 4:4555

2. Bogoyevitch MA (2006) The isoform-specific functions of the cJun N-terminal kinases (JNKs): differences revealed by gene targeting. Bioessays. 28(9):923-934

3. Bodmer D, Brors D, Bodmer M, Ryan AF (2002) Rescue of auditory hair cells from ototoxicity by CEP-11 004, an inhibitor of the JNK signaling pathway. Laryngo-rhino-otologie. 81(12):853-856

4. Eshraghi AA, Wang J, Adil E, He J, Zine A, Bublik M, Bonny C, Puel JL, Balkany TJ, van de Water T (2007) Blocking c-Jun-Nterminal kinase signaling can prevent hearing loss induced by both electrode insertion trauma and neomycin ototoxicity. Hear Res 226(1-2):168-177

5. Wang J, Van de Water TR, Bonny C, de Ribaupierre F, Puel JL, Zine A (2003) A peptide inhibitor of c-Jun N-terminal kinase protects against both aminoglycoside and acoustic traumainduced auditory hair cell death and hearing loss. J Neurosci 23(24):8596-8607

6. Kanashiro A, Franchin M, Bassi GS, Reis Santana DA, Cunha TM, Cunha FQ, Ulloa L, Rodrigues GJ (2018) Inhibition of spinal p38 MAPK prevents articular neutrophil infiltration in experimental arthritis via sympathetic activation. Fundam Clin Pharmacol 32(2): 155-162
7. Church AC, Wadsworth R, Bryson G, Welsh DJ, Peacock AJ (2012) P38 MAPK: an important pathway in the pathobiology of pulmonary hypertension and pulmonary vascular remodelling. Thorax. 67(Suppl 2):A19

8. Lamb JA, Ventura J-J, Hess P, Flavell RA, Davis RJ (2003) JunD mediates survival signaling by the JNK signal transduction pathway. Mol Cell 11(6):1479-1489

9. Sancho R, Nateri AS, de Vinuesa AG, Aguilera C, Nye E, Spencer-Dene B, Behrens A (2009) JNK signalling modulates intestinal homeostasis and tumourigenesis in mice. EMBO $\mathrm{J}$ 28(13):1843-1854

10. Hull-Thompson J, Muffat J, Sanchez D, Walker DW, Benzer S, Ganfornina MD, Jasper H (2009) Control of metabolic homeostasis by stress signaling is mediated by the lipocalin NLaz. PLoS Genet 5(4):e1000460

11. Lee J, Sun C, Zhou Y, Lee J, Gokalp D, Herrema H, Park SW, Davis RJ, Ozcan U (2011) p38 MAPK-mediated regulation of Xbp1s is crucial for glucose homeostasis. Nat Med 17(10):1251-1260

12. Mudgett JS, Ding J, Guh-Siesel L, Chartrain NA, Yang L, Gopal S et al (2000) Essential role for p38alpha mitogen-activated protein kinase in placental angiogenesis. Proc Natl Acad Sci 97(19): 10454-10459

13. Kuan CY, Yang DD, Samanta Roy DR, Davis RJ, Rakic P, Flavell RA (1999) The Jnk1 and Jnk2 protein kinases are required for regional specific apoptosis during early brain development. Neuron. 22(4):667-676

14. Greenblatt MB, Shim J-H, Zou W, Sitara D, Schweitzer M, Hu D et al (2010) The p38 MAPK pathway is essential for skeletogenesis and bone homeostasis in mice. J Clin Invest 120(7):2457-2473

15. Tong C, Yin Z, Song Z, Dockendorff A, Huang C, Mariadason J et al (2007) c-Jun NH2-terminal kinase 1 plays a critical role in intestinal homeostasis and tumor suppression. Am J Pathol 171(1):297-303

16. Maruyama M, Yagasaki Y, Sudo T, Osada H (2003) Renal abnormalities in mice caused by insufficiency of p38alpha. J Recept Signal Transduct Res 23(2-3):173-183

17. Tuncman G, Hirosumi J, Solinas G, Chang L, Karin M, Hotamisligil GS (2006) Functional in vivo interactions between JNK1 and JNK2 isoforms in obesity and insulin resistance. Proc Natl Acad Sci 103(28):10741-10746

18. Lim AKH, Ma FY, Nikolic-Paterson DJ, Ozols E, Young MJ, Bennett BL, Friedman GC, Tesch GH (2011) Evaluation of JNK blockade as an early intervention treatment for type 1 diabetic nephropathy in hypertensive rats. Am J Nephrol 34(4):337-346

19. Ijaz A, Tejada T, Catanuto P, Xia X, Elliot SJ, Lenz O et al (2009) Inhibition of c-Jun $\mathrm{N}$-terminal kinase improves insulin sensitivity but worsens albuminuria in experimental diabetes. Kidney Int 75(4):381-388

20. Cohen SB, Cheng T-T, Chindalore V, Damjanov N, BurgosVargas R, Delora P, Zimany K, Travers H, Caulfield JP (2009) Evaluation of the efficacy and safety of pamapimod, a p38 MAP kinase inhibitor, in a double-blind, methotrexate-controlled study of patients with active rheumatoid arthritis. Arthritis Rheum 60(2): 335-344

21. Bradham CA, Stachlewitz RF, Gao W, Qian T, Jayadev S, Jenkins $\mathrm{G}$ et al (1997) Reperfusion after liver transplantation in rats differentially activates the mitogen-activated protein kinases. Hepatology. 25(5):1128-1135

22. Chang L, Kamata H, Solinas G, Luo J-L, Maeda S, Venuprasad K et al (2006) The E3 ubiquitin ligase itch couples JNK activation to TNFalpha-induced cell death by inducing c-FLIP(L) turnover. Cell. 124(3):601-613

23. Ventura J-J, Hubner A, Zhang C, Flavell RA, Shokat KM, Davis RJ (2006) Chemical genetic analysis of the time course of signal transduction by JNK. Mol Cell 21(5):701-710 
24. Tomida T, Takekawa M, Saito H (2015) Oscillation of p38 activity controls efficient pro-inflammatory gene expression. Nat Commun 6:8350

25. Liu H, Lo CR, Czaja MJ (2002) NF-kappaB inhibition sensitizes hepatocytes to TNF-induced apoptosis through a sustained activation of JNK and c-Jun. Hepatology. 35(4):772-778

26. Shinohara M, Ybanez MD, Win S, Than TA, Jain S, Gaarde WA et al (2010) Silencing glycogen synthase kinase-3beta inhibits acetaminophen hepatotoxicity and attenuates JNK activation and loss of glutamate cysteine ligase and myeloid cell leukemia sequence 1. J Biol Chem 285(11):8244-8255

27. Ichijo H, Nishida E, Irie K, Dijke ten P, Saitoh M, Moriguchi T et al (1997) Induction of apoptosis by ASK1, a mammalian MAPKKK that activates SAPK/JNK and p38 signaling pathways. Science. 275(5296):90-94

28. Shiizaki S, Naguro I, Ichijo H (2013) Activation mechanisms of ASK1 in response to various stresses and its significance in intracellular signaling. Adv Biol Regul 53(1):135-144

29. Jarvis RM, Hughes SM, Ledgerwood EC (2012) Peroxiredoxin 1 functions as a signal peroxidase to receive, transduce, and transmit peroxide signals in mammalian cells. Free Radic Biol Med 53(7): $1522-1530$

30. Nadeau PJ, Charette SJ, Landry J (2009) REDOX reaction at ASK1-Cys250 is essential for activation of JNK and induction of apoptosis. Mol Biol Cell 20(16):3628-3637

31. Kekulandara DN, Nagi S, Seo H, Chow CS, Ahn Y-H (2018) Redox-inactive peptide disrupting Trx1-Ask1 interaction for selective activation of stress signaling. Biochemistry. 57(5):772-780

32. Fra A, Yoboue ED, Sitia R (2017) Cysteines as redox molecular switches and targets of disease. Front Mol Neurosci 10:167-167

33. Kim SY, Kim TJ, Lee K-Y (2008) A novel function of peroxiredoxin 1 (Prx-1) in apoptosis signal-regulating kinase 1 (ASK1)-mediated signaling pathway. FEBS Lett 582(13):1913-1918

34. Saitoh M, Nishitoh H, Fujii M, Takeda K, Tobiume K, Sawada Y, Kawabata M, Miyazono K, Ichijo H (1998) Mammalian thioredoxin is a direct inhibitor of apoptosis signal-regulating kinase (ASK) 1. EMBO J 17(9):2596-2606

35. Song JJ, Lee YJ (2003) Differential role of glutaredoxin and thioredoxin in metabolic oxidative stress-induced activation of apoptosis signal-regulating kinase 1. Biochem J 373(Pt 3):845-853

36. Liu Y, Min W (2002) Thioredoxin promotes ASK1 ubiquitination and degradation to inhibit ASK1-mediated apoptosis in a redox activity-independent manner. Circ Res 90(12):1259-1266

37. Mullen L, Hanschmann E-M, Lillig CH, Herzenberg LA, Ghezzi P (2015) Cysteine oxidation targets peroxiredoxins 1 and 2 for exosomal release through a novel mechanism of redoxdependent secretion. Mol Med 21(1):98-108

38. Kylarova S, Kosek D, Petrvalska O, Psenakova K, Man P, Vecer J, Herman P, Obsilova V, Obsil T (2016) Cysteine residues mediate high-affinity binding of thioredoxin to ASK1. FEBS J 283(20): 3821-3838

39. Tobiume K, Saitoh M, Ichijo H (2002) Activation of apoptosis signal-regulating kinase 1 by the stress-induced activating phosphorylation of pre-formed oligomer. J Cell Physiol 191(1):95-104

40. Kim H, Oh Y, Kim K, Jeong S, Chon S, Kim D, Jung MH, Pak YK, Ha J, Kang I, Choe W (2015) Cyclophilin A regulates JNK/ p38-MAPK signaling through its physical interaction with ASK1. Biochem Biophys Res Commun 464(1):112-117

41. Nakagawa H, Maeda S, Hikiba Y, Ohmae T, Shibata W, Yanai A, Sakamoto K, Ogura K, Noguchi T, Karin M, Ichijo H, Omata M (2008) Deletion of apoptosis signal-regulating kinase 1 attenuates acetaminophen-induced liver injury by inhibiting c-Jun N-terminal kinase activation. Gastroenterology. 135(4):1311-1321

42. Tobiume K, Matsuzawa A, Takahashi T, Nishitoh H, Morita K-I, Takeda K et al (2001) ASK1 is required for sustained activations of JNK/p38 MAP kinases and apoptosis. EMBO Rep 2(3):222228

43. He P, Zeng B, Zhang X-L, Fang D-L, Zhou X-Q, Wan K-Q, Tian WG (2016) Protective effect of apoptosis signal-regulating kinase 1 inhibitor against mice liver injury. Asian Pac J Trop Med 9(3): 283-287

44. Izumiya $\mathrm{Y}$, Kim S, Izumi Y, Yoshida K, Yoshiyama M, Matsuzawa A, Ichijo H, Iwao H (2003) Apoptosis signalregulating kinase 1 plays a pivotal role in angiotensin II-induced cardiac hypertrophy and remodeling. Circ Res 93(9):874-883

45. Toyama K, Koibuchi N, Hasegawa Y, Uekawa K, Yasuda O, Sueta D et al (2015) ASK1 is involved in cognitive impairment caused by long-term high-fat diet feeding in mice. Sci Rep 5:10844

46. Hasegawa Y, Toyama K, Uekawa K, Ichijo H, Kim-Mitsuyama S (2018) Role of ASK $1 / p 38$ cascade in a mouse model of Alzheimer's disease and brain aging. J Alzheimers Dis 61(1): 259-263

47. Yamaguchi O, Higuchi Y, Hirotani S, Kashiwase K, Nakayama H, Hikoso S et al (2003) Targeted deletion of apoptosis signalregulating kinase 1 attenuates left ventricular remodeling. Proc Natl Acad Sci 100(26):15883-15888

48. Terada Y, Inoshita S, Kuwana H, Kobayashi T, Okado T, Ichijo H, Sasaki S (2007) Important role of apoptosis signal-regulating kinase 1 in ischemic acute kidney injury. Biochem Biophys Res Commun 364(4):1043-1049

49. Tobiume K, Inage T, Takeda K, Enomoto S, Miyazono K, Ichijo H (1997) Molecular cloning and characterization of the mouse apoptosis signal-regulating kinase 1. Biochem Biophys Res Commun 239(3):905-910

50. Ma FY, Tesch GH, Nikolic-Paterson DJ (2014) ASK1/p38 signaling in renal tubular epithelial cells promotes renal fibrosis in the mouse obstructed kidney. Am J Physiol Renal Physiol 307(11): F1263-F1273

51. Noguchi H, Yamada S, Nabeshima A, Guo X, Tanimoto A, Wang K-Y, Kitada S, Tasaki T, Takama T, Shimajiri S, Horlad H, Komohara Y, Izumi H, Kohno K, Ichijo H, Sasaguri Y (2014) Depletion of apoptosis signal-regulating kinase 1 prevents bile duct ligation-induced necroinflammation and subsequent peribiliary fibrosis. Am J Pathol 184(3):644-661

52. Guo X, Harada C, Namekata K, Matsuzawa A, Camps M, Ji H, Swinnen D, Jorand-Lebrun C, Muzerelle M, Vitte PA, Rückle T, Kimura A, Kohyama K, Matsumoto Y, Ichijo H, Harada T (2010) Regulation of the severity of neuroinflammation and demyelination by TLR-ASK1-p38 pathway. EMBO Mol Med 2(12):504 515

53. Kadowaki H, Nishitoh H, Urano F, Sadamitsu C, Matsuzawa A, Takeda K, Masutani H, Yodoi J, Urano Y, Nagano T, Ichijo H (2005) Amyloid beta induces neuronal cell death through ROSmediated ASK1 activation. Cell Death Differ 12(1):19-24

54. Mnich SJ, Blanner PM, Hu LG, Shaffer AF, Happa FA, O'Neil S, Ukairo O, Weiss D, Welsh E, Storer C, Mbalaviele G, Ichijo H, Monahan JB, Hardy MM, Eda H (2010) Critical role for apoptosis signal-regulating kinase 1 in the development of inflammatory $\mathrm{K} / \mathrm{BxN}$ serum-induced arthritis. Int Immunopharmacol 10(10): $1170-1176$

55. Izumi $\mathrm{Y}$, Kim S, Yoshiyama M, Izumiya $\mathrm{Y}$, Yoshida K, Matsuzawa A, Koyama H, Nishizawa Y, Ichijo H, Yoshikawa J, Iwao H (2003) Activation of apoptosis signal-regulating kinase 1 in injured artery and its critical role in neointimal hyperplasia. Circulation. 108(22):2812-2818

56. Toyama K, Koibuchi N, Uekawa K, Hasegawa Y, Kataoka K, Katayama $\mathrm{T}$ et al (2014) Apoptosis signal-regulating kinase 1 is a novel target molecule for cognitive impairment induced by chronic cerebral hypoperfusion. Arterioscler Thromb Vasc Biol 34(3):616-625 
57. Starosyla SA, Volynets GP, Lukashov SS, Gorbatiuk OB, Golub AG, Bdzhola VG et al (2015) Identification of apoptosis signalregulating kinase 1 (ASK1) inhibitors among the derivatives of benzothiazol-2-yl-3-hydroxy-5-phenyl-1,5-dihydro-pyrrol-2-one. Bioorg Med Chem 23(10):2489-2497

58. Tesch GH, Ma FY, Han Y, Liles JT, Breckenridge DG, NikolicPaterson DJ (2015) ASK1 inhibitor halts progression of diabetic nephropathy in Nos3-deficient mice. Diabetes. 64(11):3903-3913

59. Liles JT, Corkey BK, Notte GT, Budas GR, Lansdon EB, HinojosaKirschenbaum F, Badal SS, Lee M, Schultz BE, Wise S, Pendem S, Graupe M, Castonguay L, Koch KA, Wong MH, Papalia GA, French DM, Sullivan T, Huntzicker EG, Ma FY, Nikolic-Paterson DJ, Altuhaifi T, Yang H, Fogo AB, Breckenridge DG (2018) ASK1 contributes to fibrosis and dysfunction in models of kidney disease. J Clin Invest 128(10):4485-4500

60. Amos LA, Ma FY, Tesch GH, Liles JT, Breckenridge DG, Nikolic-Paterson DJ, Han Y (2018) ASK1 inhibitor treatment suppresses $\mathrm{p} 38 / \mathrm{JNK}$ signalling with reduced kidney inflammation and fibrosis in rat crescentic glomerulonephritis. J Cell Mol Med 22(9):4522-4533

61. Budas GR, Boehm M, Kojonazarov B, Viswanathan G, Tian X, Veeroju S et al (2018) ASK1 inhibition halts disease progression in preclinical models of pulmonary arterial hypertension. Am J Respir Crit Care Med 197(3):373-385

62. Xie Y, Ramachandran A, Breckenridge DG, Liles JT, Lebofsky M, Farhood A, Jaeschke H (2015) Inhibitor of apoptosis signalregulating kinase 1 protects against acetaminophen-induced liver injury. Toxicol Appl Pharmacol 286(1):1-9

63. Gerczuk PZ, Breckenridge DG, Liles JT, Budas GR, Shryock JC, Belardinelli L et al (2012) An apoptosis signal-regulating kinase 1 inhibitor reduces cardiomyocyte apoptosis and infarct size in a rat ischemia-reperfusion model. J Cardiovasc Pharmacol 60(3):276-282

64. Chertow GM, Pergola PE, Chen F, Kirby BJ, Sundy JS, Patel UD (2019) Effects of selonsertib in patients with diabetic kidney disease. J Am Soc Nephrol 30(10):1980-1990

65. Schuster S, McGeough MD, Johnson CD, Zagorska A, Budas G, Hoffman $\mathrm{HM}$ et al (2017) Apoptosis signal-regulating kinase 1 (ASK1) inhibition reduces liver fibrosis and apoptosis in a NLRP3 mutant model of NASH. J Hepatol 66(1):S608-S609

66. Younossi ZM, Stepanova M, Lawitz E, Charlton M, Loomba R, Myers RP et al (2018) Improvement of hepatic fibrosis and patient-reported outcomes in non-alcoholic steatohepatitis treated with selonsertib. Liver Int 38(10): 1849-1859

67. Loomba R, Lawitz E, Mantry PS, Jayakumar S, Caldwell SH, Arnold H, Diehl AM, Djedjos CS, Han L, Myers RP, Subramanian GM, McHutchison J, Goodman ZD, Afdhal NH, Charlton MR, GS-US-384-1497 Investigators (2018) The ASK1 inhibitor selonsertib in patients with nonalcoholic steatohepatitis: a randomized, phase 2 trial. Hepatology. 67(2):549-559

68. Rosenkranz S, Feldman J, McLaughlin V, Rischard F, White J, Ebrahimi R et al (2017) The ARROW study: a phase 2, prospective, randomized, double-blind, placebo-controlled study of selonsertib in subjects with pulmonary arterial hypertension. Eur Respir J 50(suppl 61):OA1983

69. Ji N, Yang Y, Cai C-Y, Lei Z-N, Wang J-Q, Gupta P et al (2019) Selonsertib (GS-4997), an ASK1 inhibitor, antagonizes multidrug resistance in ABCB1- and ABCG2-overexpressing cancer cells. Cancer Lett 440-441:82-93

70. Nygaard G, Di Paolo JA, Hammaker D, Boyle DL, Budas G, Notte GT et al (2018) Regulation and function of apoptosis signal-regulating kinase 1 in rheumatoid arthritis. Biochem Pharmacol 151:282-290

71. Fujisawa T, Takahashi M, Tsukamoto Y, Yamaguchi N, Nakoji M, Endo M, Kodaira H, Hayashi Y, Nishitoh H, Naguro I, Homma K, Ichijo H (2016) The ASK1-specific inhibitors K811 and K812 prolong survival in a mouse model of amyotrophic lateral sclerosis. Hum Mol Genet 25(2):245-253

72. Hayakawa Y, Hirata Y, Sakitani K, Nakagawa H, Nakata W, Kinoshita H, Takahashi R, Takeda K, Ichijo H, Maeda S, Koike $\mathrm{K}$ (2012) Apoptosis signal-regulating kinase-1 inhibitor as a potent therapeutic drug for the treatment of gastric cancer. Cancer Sci 103(12):2181-2185

73. Eapen MS, Kota A, Vindin H, McAlinden KD, Xenaki D, Oliver BG, Deshpande DA, Sohal SS, Sharma P (2018) Apoptosis signal-regulating kinase 1 inhibition attenuates human airway smooth muscle growth and migration in chronic obstructive pulmonary disease. Clin Sci 132(14):1615-1627

74. Terao Y, Suzuki H, Yoshikawa M, Yashiro H, Takekawa S, Fujitani Y et al (2012) Design and biological evaluation of imidazo[1,2-a]pyridines as novel and potent ASK1 inhibitors. Bioorg Med Chem Lett 22(24):7326-7329

75. Lenzen S (2008) The mechanisms of alloxan- and streptozotocininduced diabetes. Diabetologia. 51(2):216-226

76. Nakayama T, Sato W, Kosugi T, Zhang L, Campbell-Thompson M, Yoshimura A, Croker BP, Johnson RJ, Nakagawa T (2009) Endothelial injury due to eNOS deficiency accelerates the progression of chronic renal disease in the mouse. Am J Physiol Renal Physiol. 296(2):F317-F327

77. Cichoż-Lach H, Michalak A (2014) Oxidative stress as a crucial factor in liver diseases. World J Gastroenterol 20(25):8082-8091

78. Ostapowicz G, Fontana RJ, Schiodt FV, Larson A, Davern TJ, Han SHB et al (2002) Results of a prospective study of acute liver failure at 17 tertiary care centers in the United States. Ann Intern Med 137(12):947-954

79. Larson AM, Polson J, Fontana RJ, Davern TJ, Lalani E, Hynan LS et al (2005) Acetaminophen-induced acute liver failure: results of a United States multicenter, prospective study. Hepatology. 42(6):1364-1372

80. Davern TJ, James LP, Hinson JA, Polson J, Larson AM, Fontana RJ et al (2006) Measurement of serum acetaminophen-protein adducts in patients with acute liver failure. Gastroenterology 130(3):687-694

81. McGill MR, Sharpe MR, Williams CD, Taha M, Curry SC, Jaeschke H (2012) The mechanism underlying acetaminopheninduced hepatotoxicity in humans and mice involves mitochondrial damage and nuclear DNA fragmentation. J Clin Invest 122(4):1574-1583

82. Hanawa N, Shinohara M, Saberi B, Gaarde WA, Han D, Kaplowitz N (2008) Role of JNK translocation to mitochondria leading to inhibition of mitochondria bioenergetics in acetaminophen-induced liver injury. J Biol Chem 283(20): $13565-13577$

83. Tag CG, Sauer-Lehnen S, Weiskirchen S, Borkham-Kamphorst E, Tolba RH, Tacke F et al (2015) Bile duct ligation in mice: induction of inflammatory liver injury and fibrosis by obstructive cholestasis. J Vis Exp 96

84. Younossi ZM, Koenig AB, Abdelatif D, Fazel Y, Henry L, Wymer M (2016) Global epidemiology of nonalcoholic fatty liver diseasemeta-analytic assessment of prevalence, incidence, and outcomes. Hepatology. 64(1):73-84

85. Yamamoto E, Dong Y-F, Kataoka K, Yamashita T, Tokutomi Y, Matsuba S, Ichijo H, Ogawa H, Kim-Mitsuyama S (2008) Olmesartan prevents cardiovascular injury and hepatic steatosis in obesity and diabetes, accompanied by apoptosis signal regulating kinase-1 inhibition. Hypertension. 52(3):573-580

86. (2019) Global, regional, and national burden of Alzheimer's disease and other dementias, 1990-2016: a systematic analysis for the Global Burden of Disease Study 2016. Lancet Neurol 18(1): 88-106

87. World Alzheimer Report 2016: improving healthcare for people living with dementia. [Internet]. Alzheimer's Disease International; 2016 [cited 2019 May 17]. Available from: www. alz.co.uk/research/WorldAlzheimerReport2016.pdf 
88. Reddy PH, Beal MF (2008) Amyloid beta, mitochondrial dysfunction and synaptic damage: implications for cognitive decline in aging and Alzheimer's disease. Trends Mol Med 14(2):45-53

89. Spuch C, Ortolano S, Navarro C (2012) New insights in the amyloid-beta interaction with mitochondria. J Aging Res 2012: 324968-324968

90. Eimer WA, Vassar R (2013) Neuron loss in the 5XFAD mouse model of Alzheimer's disease correlates with intraneuronal Abeta42 accumulation and Caspase-3 activation. Mol Neurodegener 8:2

91. Jawhar S, Trawicka A, Jenneckens C, Bayer TA, Wirths O (2012) Motor deficits, neuron loss, and reduced anxiety coinciding with axonal degeneration and intraneuronal Abeta aggregation in the 5XFAD mouse model of Alzheimer's disease. Neurobiol Aging 33(1):196.e29-196.e40

92. Hu X, Weng Z, Chu CT, Zhang L, Cao G, Gao Y et al (2011) Peroxiredoxin-2 protects against 6-hydroxydopamine-induced dopaminergic neurodegeneration via attenuation of the apoptosis signal-regulating kinase (ASK1) signaling cascade. J Neurosci 31(1):247-261

93. Zhang Q-S, Eaton GJ, Diallo C, Freeman TA (2016) Stressinduced activation of apoptosis signal-regulating kinase 1 promotes osteoarthritis. J Cell Physiol 231(4):944-953

94. Zhao W, Beers DR, Appel SH (2013) Immune-mediated mechanisms in the pathoprogression of amyotrophic lateral sclerosis. J NeuroImmune Pharmacol 8(4):888-899

95. Veglianese P, Coco Lo D, Bao Cutrona M, Magnoni R, Pennacchini D, Pozzi B et al (2006) Activation of the p38MAPK cascade is associated with upregulation of TNF alpha receptors in the spinal motor neurons of mouse models of familial ALS. Mol Cell Neurosci 31(2):218-231

96. Holasek SS, Wengenack TM, Kandimalla KK, Montano C, Gregor DM, Curran GL, Poduslo JF (2005) Activation of the stress-activated MAP kinase, p38, but not JNK in cortical motor neurons during early presymptomatic stages of amyotrophic lateral sclerosis in transgenic mice. Brain Res 1045(1-2):185-198

97. Wengenack TM, Holasek SS, Montano CM, Gregor D, Curran GL, Poduslo JF (2004) Activation of programmed cell death markers in ventral horn motor neurons during early presymptomatic stages of amyotrophic lateral sclerosis in a transgenic mouse model. Brain Res 1027(1-2):73-86

98. Nishitoh H, Kadowaki H, Nagai A, Maruyama T, Yokota T, Fukutomi H, Noguchi T, Matsuzawa A, Takeda K, Ichijo H (2008) ALS-linked mutant SOD1 induces ER stress- and ASK1dependent motor neuron death by targeting Derlin-1. Genes Dev 22(11):1451-1464

99. Hogg MC, Halang L, Woods I, Coughlan KS, Prehn JHM (2018) Riluzole does not improve lifespan or motor function in three ALS mouse models. Amyotroph Lateral Scler Frontotemporal Degener 19(5-6):438-445

100. Ito H, Wate R, Zhang J, Ohnishi S, Kaneko S, Ito H, Nakano S, Kusaka H (2008) Treatment with edaravone, initiated at symptom onset, slows motor decline and decreases SOD1 deposition in ALS mice. Exp Neurol 213(2):448-455

101. Brown KK, Heitmeyer SA, Hookfin EB, Hsieh L, Buchalova M, Taiwo YO et al (2008) P38 MAP kinase inhibitors as potential therapeutics for the treatment of joint degeneration and pain associated with osteoarthritis. J Inflamm 5:22-22

102. Christensen AD, Haase C, Cook AD, Hamilton JA (2016) K/BxN serum-transfer arthritis as a model for human inflammatory arthritis. Front Immunol 7:213-213

103. Aya K, Alhawagri M, Hagen-Stapleton A, Kitaura H, Kanagawa O, Novack DV (2005) NF-(kappa)B-inducing kinase controls lymphocyte and osteoclast activities in inflammatory arthritis. J Clin Invest 115(7):1848-1854

104. Brand DD, Latham KA, Rosloniec EF (2007) Collagen-induced arthritis. Nat Protoc 2(5):1269-1275
105. Morita K, Miyamoto T, Fujita N, Kubota Y, Ito K, Takubo K et al (2007, 204) Reactive oxygen species induce chondrocyte hypertrophy in endochondral ossification. J Exp Med. The Rockefeller University Press (7):1613-1623

106. Tsou H-K, Chen H-T, Chang C-H, Yang W-Y, Tang C-H (2012) Apoptosis signal-regulating kinase 1 is mediated in TNF-alphainduced CCL2 expression in human synovial fibroblasts. J Cell Biochem 113(11):3509-3519

107. Eaton GJ, Zhang Q-S, Diallo C, Matsuzawa A, Ichijo H, Steinbeck MJ et al (2014) Inhibition of apoptosis signalregulating kinase 1 enhances endochondral bone formation by increasing chondrocyte survival. Cell Death Dis 5:e1522

108. Yan F, Gao H, Zhao H, Bhatia M, Zeng Y (2018) Roles of airway smooth muscle dysfunction in chronic obstructive pulmonary disease. J Transl Med 16(1):262

109. Metz RP, Patterson JL, Wilson E (2012) Vascular smooth muscle cells: isolation, culture, and characterization. Methods Mol Biol 843:169-176

110. Tulis DA (2007) Rat carotid artery balloon injury model. Methods Mol Med 139:1-30

111. Nakagawa H, Hirata Y, Takeda K, Hayakawa Y, Sato T, Kinoshita H, Sakamoto K, Nakata W, Hikiba Y, Omata M, Yoshida H, Koike K, Ichijo H, Maeda S (2011) Apoptosis signal-regulating kinase 1 inhibits hepatocarcinogenesis by controlling the tumorsuppressing function of stress-activated mitogen-activated protein kinase. Hepatology. 54(1):185-195

112. Jiang C-F, Wen L-Z, Yin C, Xu W-P, Shi B, Zhang X, Xie WF (2016) Apoptosis signal-regulating kinase 1 mediates the inhibitory effect of hepatocyte nuclear factor- $4 \alpha$ on hepatocellular carcinoma. Oncotarget. 7(19):27408-27421

113. Hayakawa Y, Hirata Y, Nakagawa H, Sakamoto K, Hikiba Y, Kinoshita $\mathrm{H}$ et al (2011) Apoptosis signal-regulating kinase 1 and cyclin D1 compose a positive feedback loop contributing to tumor growth in gastric cancer. Proc Natl Acad Sci 108(2):780 785

114. Kamiyama M, Shirai T, Tamura S, Suzuki-Inoue K, Ehata S, Takahashi K et al (2017) ASK1 facilitates tumor metastasis through phosphorylation of an ADP receptor P2Y12 in platelets. Cell Death Differ 24(12):2066-2076

115. Naik MU, Patel P, Derstine R, Turaga R, Chen X, Golla K, Neeves KB, Ichijo H, Naik UP (2017) Ask1 regulates murine platelet granule secretion, thromboxane A2 generation, and thrombus formation. Blood. 129(9):1197-1209

116. Hattori K, Naguro I, Okabe K, Funatsu T, Furutani S, Takeda K et al (2016) ASK1 signalling regulates brown and beige adipocyte function. Nat Commun 7:11158-11158

117. Makena PS, Gorantla VK, Ghosh MC, Bezawada L, Kandasamy K, Balazs L, Luellen CL, Thompson KE, Parthasarathi K, Ichijo H, Waters CM, Sinclair SE (2012) Deletion of apoptosis signalregulating kinase-1 prevents ventilator-induced lung injury in mice. Am J Respir Cell Mol Biol 46(4):461-469

118. Johnson GL, Nakamura K (2007) The c-Jun kinase/stressactivated pathway: regulation, function and role in human disease. Biochim Biophys Acta 1773(8):1341-1348

119. Liu Z, Shi S, Zhu H, Chen Y, Zhang Y, Zheng Z et al (2018) Novel ASK1 inhibitor AGI-1067 attenuates AGE-induced fibrotic response by suppressing the MKKs/p38 MAPK pathway in human coronary arterial smooth muscle cells. Int Heart J 59(6):14161424

120. Gujral JS, Knight TR, Farhood A, Bajt ML, Jaeschke H (2002) Mode of cell death after acetaminophen overdose in mice: apoptosis or oncotic necrosis? Toxicol Sci 67(2):322-328

Publisher's note Springer Nature remains neutral with regard to jurisdictional claims in published maps and institutional affiliations. 